\title{
BODY DENSITY DIFFERENCES BETWEEN NEGRO AND CAUCASIAN PROFESSIONAL FOOTBALL PLAYERS
}

\author{
J. ADAMS* ${ }^{*}$ K. M. BAGNALL, PhD**, K. D. MCFADDEN, PhDt and M. MOTTOLA, MSc $\S$ \\ *Medical Student, University of Alberta, Canada \\ * *Assistant Professor, Department of Anatomy, University of Alberta, Canada \\ tProfessor, Department of Anatomy, University of Alberta, Canada \\ $\S$ Graduate Student, Department of Anatomy, University of Alberta, Canada
}

\begin{abstract}
Other workers have shown that the bone density for the average negro is greater than for the average caucasian. This would lead to greater values of body density for the average negro but it is confused because the average negro has a different body form (and consequently different proportions of body components) compared with the average caucasian. This study of body density of a group of professional Canadian football players investigates whether or not to separate negroes from caucasians when considering the formation of regression equations for prediction of body density. Accordingly, a group of 7 negroes and 7 caucasians were matched somatotypically and a comparison was made of their body density values obtained using a hydrostatic weighing technique and a closed-circuit helium dilution technique for measuring lung volumes. The results show that if somatotype is taken into account then no significant difference in body density values is found between negro and caucasian professional football players. The players do not have to be placed in separate groups but it remains to be seen whether or not these results apply to general members of the population.
\end{abstract}

\section{INTRODUCTION}

A recent paper (Adams et al, 1981) reported work on the body density values for a group of professional players of Canadian Football. This game differs from American "grid-iron" football in a number of ways, summarised in Fig. 1, and will be seen to differ obviously from British Rugby and Association football. It was found that the use of Siri's (1956) equation for the prediction of body fat content from these values was inappropriate because many negative estimates were produced from high values of body density. It was suggested that these high values were related to a slight increase in skeletal proportions (using the figures of
Welham and Behnke, 1942) due to the daily routine of heavy exercise and violent body contact (Bassett, 1966, 1968). Furthermore, the results of skinfold measurements on these players suggested that there were normal deposits of subcutaneous fat (according to the work of Pascale et al, 1956; Chinn and Allen, 1960; Durnin and Womersley, 1974). Currently, attempts are being made to study more effectively the variation that exists in body components (muscle, bone, fat) and their respective densities using possibly a C.T. scanner. It seems clear, however, that Siri's equation is inappropriate for some of the extremes of body form found in a population such as professional football players. 
What's The Difference

U.S. FOOTBALL

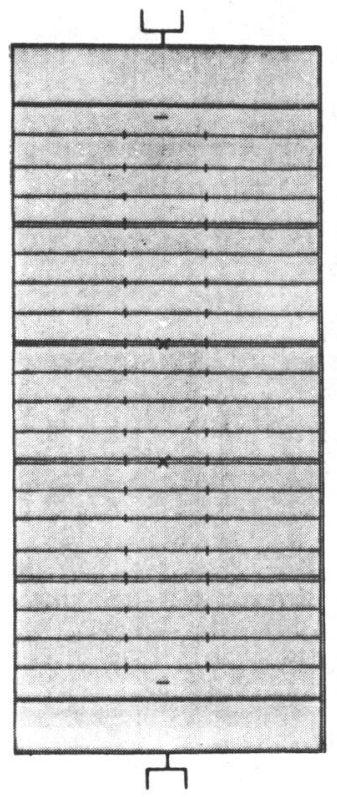

Figure 1

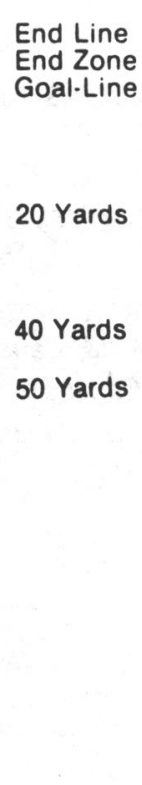

End Zone

Goal-Line

20 Yards

40 Yards

50 Yards

CANADIAN FOOTBALL

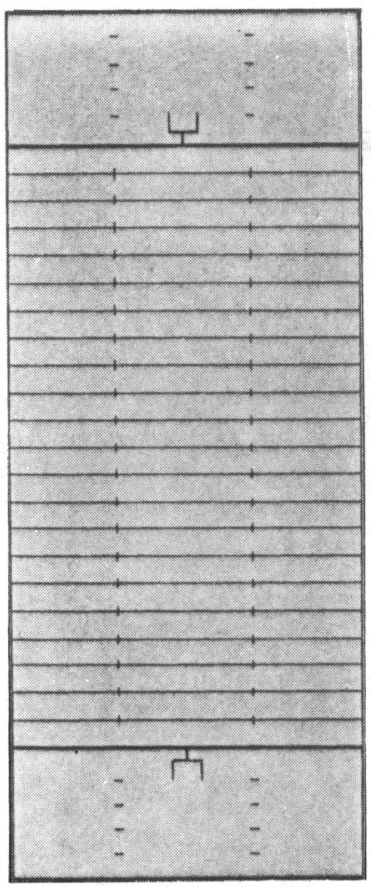

Deadline

End Zone

Goal Line

25 Yards

45 Yards

55 Yards

U.S. FOOTBALL

11 men.

\section{MUMBER OF PLAYERS}

12 men (extra man is a backfielder).

SIZE OF FIELD

100 yards long plus two $\quad 110$ yards long. plus two 10yard end zones, and . 25-yard end zones, and $52-1 / 3$ yards wide. 65 yards wide.

DOWNS

4 downs to make 10 yards. 3 downs to make 10 yards. SCORING

Touchdown, 6 pts; field Touchdown, 6 pts; field goal, goal, 3 pts; safoty, 3 pts; safety, 2 pts; single or 2 pts: PAT, 1 pt. rouge, 1 pt: PAT (or convert). 1 pt. by kick. 2 pts, by pass SINGLE POINT

(rouge)

None

a) When punt or missed field oal by attacking team goes into end zone, where delensive player recovers and is tackled: b) when punt or missed field goals go out of bounds in end zone. BACKFIELD MOTION At the snap, only one back AH players in backfield may be
of attacking team may be in motion-backwards the ball is put into play. or laterally.

\section{PUNT}

Punts may be allowed to roll dead; may be received returned with aid of blocking by returning team Ball may not be recovered legally by punting team, unless fumbled by receiving team. Punted ball going across goal line is a touchback.
There is no fair catch which accounts for average of 15 punt returns per game. lacklers must remain outside 5-yard area around receiver until he has touched ball, except that the punter - or anyone playing "onside" to punter-may legally ecover ball. Punt returner must run ball (or kick it) out of end zone or concede a single point (rouge). The rule on unsuccessful field goals is similar in all these respects. Blocking above the waist is permitted on punt returns.
Davidson et al (1973) conclude that there have not been sufficient direct analyses of human skeletons to allow accurate statements to be made on the range of variation. However, they also report that in the USA negroes have on average a slightly heavier skeleton than whites. Tanner (1962) also reports that negro bones throughout are denser than white and extends this by recording that negroes are at birth ahead of whites in skeletal ossification. However, he associated this with advancement of motor behaviour which supports the concept of bone deposition being associated with exercise (Bassett, 1966, 1968).

Adams et al (1981) studied a mixed group of negro and caucasian subjects and wondered if, in any future work relating to body density and fat content, these two groups should be separated, especially as the skeletal component of the body plays such an important role in determining body density. However, in any group of subjects, this is difficult to assess unless body form is given consideration since different proportions of body components will produce different body density values. Accordingly, this project was designed to study the difference in body density between negroes and caucasians who have been matched for somatotype.

\section{METHOD}

Seven negro and seven caucasian professional Canadian football players were closely matched for somatotype according to the method described by Heath and Carter (1967). The somatotypes were plotted on a somatochart by the method of Hebbelinck et al (1972) (Fig. 2). A conventional hydrostatic weighing technique coupled with a closed-circuit helium dilution method for measuring lung volumes in water, was used to measure the body density of each player (Mottola, 1980; Adams et al, 1981). See Table I. A student's t-test analysis for matched pairs was applied to the body density values.

\section{RESULTS}

Figure 2 shows that the somatotypes of the paired negro and caucasian players were closely matched and justifies the use of matched pairs analysis. Table I shows the body density values for each of the paired groups. These values are relatively high but similar values have been reported whenever professional football players have been studied (Welham and Behnke, 1942). The student's t-test for matched pairs revealed no significant difference for body density values between the negro and caucasian players $(t=1.191)$. 


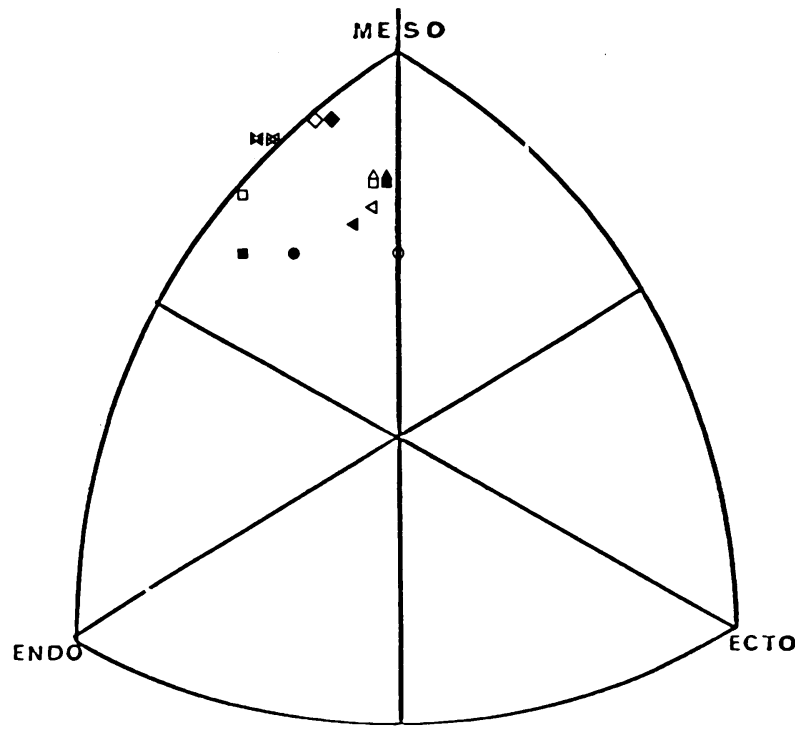

Fig. 2: The paired somatotypes. Similar symbols represent matched pairs. Clear symbols = caucasian. Black symbo/s = negro.

\section{DISCUSSION}

The results of this study show that when negro and caucasian football players are matched somatotypically there is no significant difference in their body density values. Any differences between somatotypically matched players is only skin deep relating to pigmentation and minor external features.

Metheny (1939) found that in the general, nonathletic population negroes have longer arms and legs (relative to stature) narrower hips and more slender calves than caucasians. This suggests that the average negro has a different somatotype from the average cau- casian, tending more towards ectomorphy. This different somatotype with its different proportions of body components will produce a different body density for the negro, possibly being greater than that for the caucasian because of its greater ectomorphic value. This study has shown that if the difference in somatotypes is eliminated then no difference exists in body density values.

Both Tanner (1964) and Davidson et al (1973) report that negroes have somewhat denser and heavier bones than caucasians. This being so, it might be expected that a negro with the same somatotype as a caucasian would have a greater body density because of the greater density of the bone. However, our results suggest that in our subjects this is not true. Tanner (1964) discussed the difference in somatotype between negroes and caucasians in terms of a different arrangement of levers for athletic events. The mechanical factors in an exercise, which affect the deposition of bone (Bassett, 1966; 1968) might be influenced by this difference in arrangement of levers, the result being a more dense skeleton in the average negro. If, as in our study, the somatotypes have been matched, then the influence of these mechanical factors might well be diminished with the skeletal densities becoming similar. Furthermore, an earlier paper (Adams et al, 1981) has shown that the body density values for our subjects are high when compared with normal population values and this was related to the heavy, rigorous, daily exercise that was undertaken by our subjects resulting in greater bone deposition. It is possible that these factors, which affect bone deposition, mask and overtake any deposition due merely to differences in bone and muscle relationships. It has been suggested that all subjects, negroes and caucasians, have more dense bones than general members of a population and it would be interesting to extend our study to a more general population to see if our findings are substantiated.

Tanner (1962) discusses the advanced ossification

\section{TABLE I}

The matched somatotypes of the two groups of seven players and their respective body densities

NEGRO

CAUCASIAN

$\begin{array}{cccc}1 & \text { II } & \text { III } & \text { BODY } \\ \text { ENDO } & \text { MESO } & \text { ECTO } & \text { DENSITY }\end{array}$

1.087

46

$4 \quad 5 \frac{1}{2}$

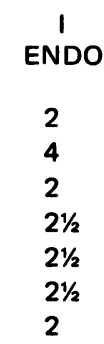

II
MESO
5
$61 / 2$
8
6
7
7
6

III


that is found in the negro at birth and which is associated with genetically determined advanced neuromuscular development; therefore it is possible that the adult negro has a more dense skeleton due to genetic reasons and not mechanical factors. We have not excluded this possibility from our study. If the negro skeleton was more dense and the subjects have been matched somatotypically then in order to maintain equal body density values, the remaining body components (muscle, connective tissue, blood vessels, etc) must alter density values towards being greater for the caucasian. Tanner (1964) disputes any internal differences in density values from a physiological viewpoint but the obvious prevalence of negroes in certain athletic events (e.g. sprinting) and their absence in others (e.g. swimming) suggest that there might be internal differences although many other factors, including mechanical arrangements, must be considered.

It is possible that the "average" negro has a greater body density than the "average" caucasian. However, it seems perfectly reasonable to us to suggest as our results indicate, that there are no differences in body density values between negro and caucasian football players if they are equated somatotypically. Any differences that appear to exist can be related to differences in body form and if this influence is removed similar values for body density are obtained. It remains to be seen whether or not these results can be extended to include subjects who do not undertake such rigorous daily activity.

\section{REFERENCES}

Adams, J., Mottola, M., Bagnall, K. and McFadden, K., 1981 "Total body fat content in a group of professional football players". (Sent for publication to the Can.J.App.Sc.Sp.).

Bassett, C., 1966 "Electromechanical factors regulating bone architecture". Third European Symposium on Calcified Tissues. Springer-Verlag, Berlin.

Bassett, C., 1968 “Biologic significance of piezoelectricity". Calc.Tiss.Res. 1: 252-272.

Chinn, K. and Allen, T., 1960 "Body fat in men from two skinfolds, weight, height and age". US Army Medical Research Laboratory Report No. 248.

Davidson, S., Passmore, R. and Brock, J., 1972. Human Nutrition and Dietetics. 5th Edition. Churchill Livingstone.

Durnin, J. V. G. A. and Womersley, J., 1974 "Body fat assessed from total body density and its estimation from skinfold thickness. Measurements on 481 men and women aged from 16 to 72 years". Br.J.Nutr. 32: 77-97.

Heath, B. and Carter, J., 1967 "A modified somatotype method". Am.J.Phys.Anthrop. 27: 57-74.

Hebbelinck, M. and Ross, W., 1972. Body Type and Performance. McMillan Co., New York.

Metheny, E., 1939 "Some differences in body proportions between American negro and white male college students as related to athletic performance". Res.Quart. 10: 41-53.

Mottola, M., 1980 "The effects of diet and exercise on the body composition of women". MSc Thesis. University of Alberta.

Pascale, L., Grossman, J., Sloane, H. and Frankel, T., 1956 "Correlations between thickness of skinfolds and body density in 88 soliders". Hum.Biol. 28: 165-176.

Siri, W. E., 1956. Advances in Biological and Medical Physics. New York, Academic Press.

Tanner, J., 1962. Growth at Adolescence. 2nd Edition. Blackwell Scientific Publications.

Tanner, J., 1964. The Physique of the Olympic Athlete. Allen and Unwin, London.

Welham, W. and Behnke, A., 1942 "The specific gravity of healthy men". JAMA 118: 498-501. 